\title{
Hematite Photoanodes: Synergetic Enhancement of Light Harvesting and Charge Management by Sandwiched with $\mathrm{Fe}_{2} \mathrm{TiO}_{5} / \mathrm{Fe}_{2} \mathrm{O}_{3} / \mathrm{Pt}$ Structures
}

Lei Wang, ${ }^{a}$ Nhat Truong Nguyen, ${ }^{\mathrm{b}}$ Xiaojuan Huang, ${ }^{\mathrm{a}}$ Patrik Schmuki, ${ }^{\mathrm{b} *}$ and Yingpu Bi ${ }^{\mathrm{a} *}$

Prof. Dr. Lei Wang, Xiaojuan Huang, Prof. Dr. Yingpu Bi

State Key Laboratory for Oxo Synthesis and Selective Oxidation, National Engineering Research Center for Fine Petrochemical Intermediates, Lanzhou Institute of Chemical Physics, Chinese Academy of Sciences, 730000 Lanzhou, China.

E-mail: yingpubi@licp.cas.cn

Nhat Truong Nguyen, Prof. Dr. Patrik Schmuki

Department of Materials Science and Engineering, WW4-LKO, University of ErlangenNuremberg, Martensstrasse 7, D-91058 Erlangen, Germany.

E-mail: schmuki@ww.uni-erlangen.de

Prof. Dr. Patrik Schmuki

Department of Chemistry, King Abdulaziz University, 80203 Jeddah, Saudi Arabia Kingdom.

Link to the published article:

https://onlinelibrary.wiley.com/doi/full/10.1002/adfm.201703527

\section{Keywords:}

hematite photoanodes, Pt nanopillar, charge separation, light absorption, photoelectrochemical water splitting. 


\begin{abstract}
Efficient charge separation and transport as well as high light absorption are key factors that determine the efficiency of photoelectrochemical (PEC) water splitting devices. Here, we have designed and fabricated a PEC device consisting of a hematite nanoporous film deposited on Pt nanopillars, followed by the decoration with a $\mathrm{Fe}_{2} \mathrm{TiO}_{5}$ passivation layer. This structure can largely improve the light absorption in the composite materials, and significantly enhance the water oxidation performance of hematite photoanodes. The $\mathrm{Fe}_{2} \mathrm{TiO}_{5}$ thin shell and Pt underlayer significantly improve the interfacial charge transfer while minimizing the hole-migration length in $\mathrm{Fe}_{2} \mathrm{O}_{3}$ photoanodes, leading to a drastically increased photocurrent density. Specially, the $\mathrm{Fe}_{2} \mathrm{TiO}_{5} / \mathrm{Fe}_{2} \mathrm{O}_{3} / \mathrm{Pt}$ photoanode yields an excellent photoresponse for PEC water splitting reactions with $1.0 \mathrm{~mA} \mathrm{~cm}^{-2}$ and $2.4 \mathrm{~mA} \mathrm{~cm}{ }^{-2}$ obtained at $1.23 \mathrm{~V}_{\mathrm{RHE}}$ and 1.6 $\mathrm{V}_{\mathrm{RHE}}$ under $\mathrm{AM} 1.5 \mathrm{G}$ illumination in $1 \mathrm{M} \mathrm{KOH}$. The resulting photocurrents are 2.5 times enhanced compared to a pristine $\mathrm{Fe}_{2} \mathrm{O}_{3}$ photoanode of the same geometry. These results demonstrate a synergistic charge transfer effect of $\mathrm{Fe}_{2} \mathrm{TiO}_{5}$ and $\mathrm{Pt}$ layers on hematite for the improvement of PEC water oxidation.
\end{abstract}




\section{Introduction}

Hematite $\left(\mathrm{a}-\mathrm{Fe}_{2} \mathrm{O}_{3}\right)$ is considered as a promising candidate for the fabrication of visible light absorbing photoelectrodes, owing to its low cost, the environmentally benign and earthabundant nature, and especially due to an almost ideal energy band gap (2.0-2.2 eV), which can absorb a large portion of the solar irradiation spectrum combined with a suitable valence band edge position for water oxidation ${ }^{[1-6]}$ In spite of these advantages, a- $\mathrm{Fe}_{2} \mathrm{O}_{3}$ photoanodes present some critical drawbacks that detrimentally affect their PEC activities, e.g. the low internal quantum efficiency (IQE), only a quarter of the theoretical limit has been achieved by $\mathrm{a}-\mathrm{Fe}_{2} \mathrm{O}_{3}$ reported so far. The low IQE of $\mathrm{a}-\mathrm{Fe}_{2} \mathrm{O}_{3}$ photoanodes has been attributed to the slow water oxidation kinetics and short lifetime of photogenerated charge carriers $(<10 \mathrm{ps})$ resulting in significant loss due to the electron-hole recombination. ${ }^{[1]}$ For an active material with short carrier diffusion length, thinning down the material can lead to an improved carrier collection, however thinner layers also result in a loss of light absorption.

To address these issues and further increase the light absorption, the use of plasmonic nanostructures, ${ }^{[7,8]}$ opal scaffolds, ${ }^{[9]}$ resonant light trapping in thin films, ${ }^{[10]}$ as well as photonic nanostructures ${ }^{[11]}$ have been demonstrated as useful strategies to improve the IQE. For instance, $\mathrm{Si}-\mathrm{Fe}_{2} \mathrm{O}_{3}$ core-shell nanowire photoelectrodes with $\mathrm{Au}$ nanoparticles embedded in the hematite shell have demonstrated a solar to hydrogen (STH) efficiency of up to $6 \% .{ }^{[12]}$ Similar approaches use plasmonics in metal-semiconductor core-shell structures, which combine a one dimensional geometry and localized surface plasmon resonance (LSPR). Alternatively ultrathin hematite films deposited on 3D nanophotonic structure can largely improve the light trapping and thus the absorption in ultrathin active materials, and at the same time provide a large surface area to accommodate the slow surface water oxidation process. $^{[11]}$ 
Conductive oxides such as fluorine-doped $\mathrm{SnO}_{2}$ (FTO) are commonly used as transport substrate materials for the deposition of semiconductor photoanodes for PEC water splitting. However, FTO has a substantially lower intrinsic conductivity compared to metal or carbon substrates ${ }^{[13]}$ Furthermore, Fermi level matching and interfacial recombination between the photoanode and the FTO conductive substrate can lead to recombination losses due to the electron back-injection into the electrolyte on the exposed areas of FTO. ${ }^{[14,15]}$ Commonly, adding an ultra-thin underlayer of $\mathrm{SiO}_{\mathrm{x}}, \mathrm{TiO}_{2}, \mathrm{Nb}_{2} \mathrm{O}_{5}$, or $\mathrm{Ga}_{2} \mathrm{O}_{3}$ has been reported to suppress the back electron injection and reduce interface recombination of hematite. ${ }^{[15,16]}$ Recently, Schuhmann et al. studied that the modification of FTO by electro-deposition of Pt nanoparticles (NPs) not only improves the conductivity of FTO, but also creates nuclei at which later semiconductor deposition can start. ${ }^{[17,18]}$ The Pt NPs mediate the transfer of photoelectrons to the back contact and thus the PEC performances of various photoanodes are increased. On the other hand efficient collection of the minority charge carriers at the surface of hematite photoanodes - this balancing the photoreactions - is needed to reduce overall carrier recombination losses.

Recently, a $\mathrm{Fe}_{2} \mathrm{TiO}_{5}$ thin layer deposited on the surface of hematite was reported. ${ }^{[19-21]}$ $\mathrm{Fe}_{2} \mathrm{TiO}_{5}$ is a n-type bandgap semiconductor with the band edge straddling the water redox potential. Moreover, it holds a more negative conduction and valence band edge compared to the hematite, and $\mathrm{Fe}_{2} \mathrm{O}_{3} / \mathrm{Fe}_{2} \mathrm{TiO}_{5}$ could form a heterojunction structure and offer a favorable valence band position to facilitate hole transport for enhanced performance. ${ }^{[20,21]}$ In conjunction with above presented strategies for enhancing the PEC performance the formation of suitable interfacial layers to 3D or nanoporous structures offers a strategy to increase light trapping upon illumination with solar energy. ${ }^{[10]}$ In this work, we introduce the modification of FTO substrate with Pt nanoparticles layer that can induce the later $\mathrm{Fe}_{2} \mathrm{O}_{3}$ deposition. This Pt decoration is used as electron transfer mediator and light trapping element. As a hole transfer mediator and hematite passivation layer we use an extremely thin $\mathrm{Fe}_{2} \mathrm{TiO}_{5}$ layer 
around the $\mathrm{Fe}_{2} \mathrm{O}_{3}$ structures. Photoanodes constructed of $\mathrm{Fe}_{2} \mathrm{TiO}_{5} / \mathrm{Fe}_{2} \mathrm{O}_{3}$ on Pt/FTO substrate give rise to a significant enhancement in PEC water splitting due to a combined effect of $\mathrm{Fe}_{2} \mathrm{TiO}_{5}$ and the double effect of the Pt decoration on charge transfer and light trapping.

\section{Results and Discussion}

Scheme 1 shows the fabrication of the a- $\mathrm{Fe}_{2} \mathrm{O}_{3}$ nanoporous film on a Pt NPs/FTO substrate. Such Pt NPs film can be produced using a facile reduction and deposition method. Briefly, an iron foil was put in a $5 \mathrm{mM} \mathrm{H}_{2} \mathrm{PtCl}_{6}$ aqueous solution, and then $\mathrm{FTO}$ substrate was put on the face of this foil. In the presence of $\mathrm{H}_{2} \mathrm{PtCl}_{6}$ solution, the replacement reaction between iron substrate and $\mathrm{PtCl}_{6}{ }^{2-}$ ions starts immediately accompanied with observable gas bubble formation. The reduced Pt NPs grow in-situ and decorate both sides of the iron foil and the FTO slide. We found this approach to be convenient and controllable to obtain various $\mathrm{Pt}$ particle sizes (30-400 nm) and geometries on the front side of the FTO substrates (Figure S1). After that, the hematite nanoporous films were synthesized as a decoration on the substrate according to a previous reported method (see Experimental). ${ }^{[22]}$ In a first step FeOOH nanofilms were produced on the Pt/FTO coated glass by a solution-based approach in a 20 $\mathrm{mM} \mathrm{Fe}\left(\mathrm{NO}_{3}\right)_{3}$ aqueous solution. In order to fabricate Fe-titanate shells on the hematite, the asgrown samples then were dropped in $\mathrm{TiCl}_{4}$ aqueous solution followed by annealing in air under $600{ }^{\circ} \mathrm{C}$ for $30 \mathrm{~min}$. Sn-doped hematite samples were obtained by annealing the $\mathrm{FeOOH}$ and $\mathrm{Ti}-\mathrm{FeOOH}$ on $\mathrm{FTO}$ or $\mathrm{Pt} / \mathrm{FTO}$ structures at $750{ }^{\circ} \mathrm{C}$ for additional 20 min to allow $\mathrm{Sn}$ diffusion from the FTO substrates.

Scanning electron microscopy (SEM) images show that a typical $\mathrm{Fe}_{2} \mathrm{O}_{3}$ film on the FTO consists of a porous structure with round and oval particles of a diameter of 50-100 nm, and a length of around $50 \mathrm{~nm}$ (Figure 1a). For plain Pt deposited on the FTO substrate, a uniform Pt NPs layer with a diameter of $\approx 50 \mathrm{~nm}$ is formed on the FTO substrate (inset of Figure $1 \mathrm{~b}$ ). For samples where the $\mathrm{Pt}$ is decorated with the $\mathrm{Fe}_{2} \mathrm{O}_{3}$ film (Figures $1 \mathrm{~b}$ and $\mathrm{S} 2$ ) an identical 
morphology to porous structure with a size of $50-100 \mathrm{~nm}$ is observed. If the $\mathrm{TiCl}_{4}$ treatment is applied and the structure is converted to iron titanate layer (Figure 1c), the particle diameter becomes smaller $(\approx 20-40 \mathrm{~nm})$ - this indicates that the $\mathrm{TiCl}_{4}$ treatment prevents sintering of the particles during annealing. For these particles, high-resolution transmission electron microscopy (HRTEM) image clearly shows the hematite crystal structure with a lattice spacing of $0.25 \mathrm{~nm}$ for the [110] lattice planes (Figure 1d). The Ti-containing ultrathin layer can be clearly seen from an area of 5-10 nm in width near the surface of nanoporous film (Figure 1d). It consists of a crystalline outerlayer with a lattice spacing of $0.35 \mathrm{~nm}$ corresponding to the (220) plane of the pseudobrookite $\left(\mathrm{Fe}_{2} \mathrm{TiO}_{5}\right)$ phase. The TEM line-scans (Figure 1f-i) show the spatial distribution of $\mathrm{Fe}, \mathrm{Ti}, \mathrm{Sn}$, and $\mathrm{O}$ elements in a single particle. Obviously a higher Ti single intensity is recorded along the particle edge (Figure 1h), while both $\mathrm{Fe}$ and $\mathrm{O}$ exhibit a fairly uniform distribution across the entire particle body (Figure if and g). These findings indicate the formation of $\mathrm{Fe}_{2} \mathrm{O}_{3}-\mathrm{Fe}_{2} \mathrm{TiO}_{5}$ core-shell structure. The composition of $\mathrm{Fe}_{2} \mathrm{TiO}_{5} / \mathrm{Fe}_{2} \mathrm{O}_{3} / \mathrm{Pt}$ sample was analyzed by SEM-EDS/mapping (Figures $1 \mathrm{j}$ and S3), and the resulting spectra reveal the presence of $\mathrm{Fe}, \mathrm{Ti}, \mathrm{Sn}, \mathrm{Pt}$ and $\mathrm{O}$ in ratios $(\approx 1: 0.7: 3: 1: 5)$. The Pt signal originates from the supporting Pt NP layer on FTO.

Figure 2a shows the X-ray diffraction (XRD) patterns of $\mathrm{Fe}_{2} \mathrm{O}_{3}, \mathrm{Fe}_{2} \mathrm{O}_{3} / \mathrm{Pt}$, and $\mathrm{Fe}_{2} \mathrm{TiO}_{5} / \mathrm{Fe}_{2} \mathrm{O}_{3} / \mathrm{Pt}$ samples. The Pt NPs layer on the FTO substrate after reduction is also shown for comparison (Figure S4). The three characteristic diffraction peaks at $2 \theta$ values of $40^{\circ}, 46^{\circ}$, and $67^{\circ}$ correspond to the (110), (200), and (220) planes of face-centered cubic (fcc) structure of platinum. ${ }^{[23]}$ The reflection peak broadening suggests that the Pt NPs are composed of nanocrystalline grains. In the case of $\mathrm{Fe}_{2} \mathrm{O}_{3} / \mathrm{Pt}$ after thermal annealing in air, the Pt phase transforms the disordered fcc structure to an ordered face-centered tetragonal (fct) structure, ${ }^{[24]}$ in line with a shift to lower $2 \theta$ values (Figure S5). The crystallite size calculated from the full width half-maximum of the Pt (110) peak is around $60 \mathrm{~nm}$ (Figure 2a). There is a slight shift to the higher $2 \theta$ values for the $\mathrm{SnO}_{\mathrm{x}}$ from FTO substrate (in line with XPS data 
discussed below). Also, no characteristic peaks of iron oxide are detected for the $\mathrm{Fe}_{2} \mathrm{O}_{3} / \mathrm{Pt}$ sample due to the low amount of crystalline iron oxide. For the $\mathrm{Fe}_{2} \mathrm{TiO}_{5} / \mathrm{Fe}_{2} \mathrm{O}_{3} / \mathrm{Pt}$ sample, a characteristic peak at $26^{\circ}$ is observed, which can be indexed to the (110) plane of pseudobrookite $\mathrm{Fe}_{2} \mathrm{TiO}_{5}$ phase formation. To further elucidate the structural features we used Raman spectroscopy. The resulting spectra (Figures 2b and S6) show peaks at 221, 242, 289, 406, 496, 610, and $656 \mathrm{~cm}^{-1}$ that can be assigned to hematite for all $\mathrm{Fe}_{2} \mathrm{O}_{3}$-based samples, which match quite well with reported values for hematite in the literature. ${ }^{[25]}$ For the $\mathrm{Fe}_{2} \mathrm{TiO}_{5} / \mathrm{Fe}_{2} \mathrm{O}_{3} / \mathrm{Pt}$ sample, the Raman bands at 297 and $410 \mathrm{~cm}^{-1}$ can be clearly resolved. These features correspond to the spectral characteristics of iron titanate. ${ }^{[26]}$ To identify the presence of $\mathrm{Fe}, \mathrm{Ti}$, and $\mathrm{Sn}$ in the $\mathrm{Fe}_{2} \mathrm{TiO}_{5} / \mathrm{Fe}_{2} \mathrm{O}_{3} / \mathrm{Pt}$ thin films, XPS scans were performed as shown in Figures $2 \mathrm{c}-\mathrm{e}$ and S7. In the Fe 2p region (Figure S7), the spectra show binding energies of $724.5 \mathrm{eV}\left(\mathrm{Fe} 2 \mathrm{p}_{1 / 2}\right)$ and $711.1 \mathrm{eV}\left(\mathrm{Fe} 2 \mathrm{p}_{3 / 2}\right)$ with a shake-up satellite line at 718.8 $\mathrm{eV}$, which is characteristic for $\mathrm{Fe}^{3+}$ in $\mathrm{Fe}_{2} \mathrm{O}_{3}$. In the Pt 4f spectra (Figure 2c), two peaks at $71.1 \mathrm{eV}$ and $74.5 \mathrm{eV}$ for the Pt NPs/FTO could be assigned to metal $\mathrm{Pt}^{0}$. It is interesting that the $\mathrm{Pt} 4 \mathrm{f}$ peaks of $\mathrm{Fe}_{2} \mathrm{TiO}_{5} / \mathrm{Fe}_{2} \mathrm{O}_{3} / \mathrm{Pt}$ sample are shifted to lower binding energies of $70.9 \mathrm{eV}$ and $74.3 \mathrm{eV}$. Such a negative binding energy shift is consistent with the results from XRD patterns (Figure 2a), indicating electron donation of Pt to the surrounding that results in a change in the electronic properties of Pt $4 \mathrm{f}$ peaks. ${ }^{[27]}$ The findings thus indicate modified electronic properties of $\mathrm{Pt}$ in the present structures. ${ }^{[28,29]}$ Moreover, the $\mathrm{Sn}^{4+}$ (Figure 2d) with two major peaks at $486.5 \mathrm{eV}\left(\mathrm{Sn} 3 \mathrm{~d}_{5 / 2}\right)$ and $495.3 \mathrm{eV}\left(\mathrm{Sn} 3 \mathrm{~d}_{3 / 2}\right)$ appears if high temperature annealing $\left(600{ }^{\circ} \mathrm{C}+750{ }^{\circ} \mathrm{C}\right)$ of the thin hematite film is carried out which allows the diffusion of Sn from the FTO substrate to the film. In Figure 2e, the $\mathrm{Fe}_{2} \mathrm{TiO}_{5} / \mathrm{Fe}_{2} \mathrm{O}_{3} / \mathrm{Pt}$ sample shows Ti $2 \mathrm{p}$ peaks at $458.4 \mathrm{eV}\left(\mathrm{Ti} 2 \mathrm{p}_{3 / 2}\right)$ and $464.7 \mathrm{eV}$ ( $\left.\mathrm{Ti} 2 \mathrm{p}_{1 / 2}\right)$ consisting with Ti in a fully oxidized $\mathrm{Ti}^{4+}$ state.

In order to examine the water oxidation performance of $\mathrm{Fe}_{2} \mathrm{TiO}_{5}$ and $\mathrm{Pt}$ underlayer on the hematite photoanodes, linear-sweep voltammogram (LSV) curves were recorded on the 
hematite photoanodes under simulated sunlight illumination ( $\mathrm{AM} 1.5 \mathrm{G}, 100 \mathrm{~mW} \mathrm{~cm}^{-2}$ ) in $1 \mathrm{M}$ $\mathrm{KOH}$ solution. All the photoanodes were annealed at $600{ }^{\circ} \mathrm{C}$ for $30 \mathrm{~min}$ and then $750{ }^{\circ} \mathrm{C}$ for 20 min. In Figure 3a, upon sweeping the potential from 0.8 to $1.7 \mathrm{~V}_{\mathrm{RHE}}$ under illumination, the pristine $\mathrm{Fe}_{2} \mathrm{O}_{3}$ photoanode on the FTO substrate shows a water oxidation onset potential of $0.8 \mathrm{~V}_{\mathrm{RHE}}$, and the photocurrent density increases from $0.5 \mathrm{~mA} \mathrm{~cm}{ }^{-2}$ at $1.23 \mathrm{~V}_{\mathrm{RHE}}$ to $0.9 \mathrm{~mA}$ $\mathrm{cm}^{-2}$ at $1.60 \mathrm{~V}_{\text {RHE }}$. For the hematite deposited on the Pt/FTO substrate, it can be clearly seen that the photocurrent over the whole potential range from $0.8 \mathrm{~V}_{\mathrm{RHE}}$ to $1.6 \mathrm{~V}_{\mathrm{RHE}}$ is significantly increased. At $1.60 \mathrm{~V}_{\mathrm{RHE}}$, the photocurrent is more than doubled from $0.9 \mathrm{~mA} \mathrm{~cm}^{-2}$ (pristine on the planar substrate) to $1.9 \mathrm{~mA} \mathrm{~cm}$. For comparison, high-temperature activation at $750{ }^{\circ} \mathrm{C}$ was carried out (this is commonly used to enhance the PEC performance of hematite photoanodes for water oxidation, by inducing Sn diffusion from FTO substrate into hematite). ${ }^{[30]}$ In order to distinguish Sn doping effects from the un-doped photoanodes, samples were also treated at a relatively lower temperature $\left(600^{\circ} \mathrm{C}\right)$ for comparison. Also in this case, the $\mathrm{Fe}_{2} \mathrm{O}_{3}$ on the Pt/FTO photoanode still shows higher values over the whole potential range compared to pristine hematite electrodes (Figure S8). At $1.5 \mathrm{~V}_{\mathrm{RHE}}$, the photocurrent density reduces to $0.3 \mathrm{~mA} \mathrm{~cm}^{-2}$ (for hematite on the $\mathrm{Pt} / \mathrm{FTO}$ ) while it only reaches $0.11 \mathrm{~mA} \mathrm{~cm}^{-2}$ for hematite on FTO. Furthermore, various particle sizes of Pt NP pillars (Figure S1) were tailored by adjusting deposition times, and the solar water splitting performance was examined as shown in Figure S9. It can be deduced that for pillars produced for $5 \mathrm{~min}$, the photocurrent density of $\mathrm{Fe}_{2} \mathrm{O}_{3} / \mathrm{Pt}$ photoanode is distinctly increased, while for shorter (2 min) and longer (10 $\mathrm{min})$ deposition, the result exhibits a lower photoresponse but still show a higher value compared to the as-prepared $\mathrm{Fe}_{2} \mathrm{O}_{3}$ on FTO substrate.

The Pt nanopillars layer on FTO alters not only electronic properties at the FTO interface but the back reflection from Pt can increase the overall light absorption. To confirm the light trapping property of Pt NPs on FTO, the optical properties were characterized by UV-vis optical absorption before and after hematite deposition as shown in Figures $3 \mathrm{~b}$ and S10. 
Indeed, for hematite deposited on Pt the devices shows a much higher light absorption than the pristine one, especially for longer wavelength $(500-700 \mathrm{~nm})$, indicating a strong light trapping effect when a Pt NPs underlayer is present. Notably, among three different sizes of Pt NPs, NPs with immersion time of 5 min and 10 min show a clear difference and they both exhibit much better light absorption properties than the $2 \mathrm{~min}$ immersion sample (Figure $\mathrm{S} 10$ ). This can be explained by the higher aspect ratio that leads to enhanced light absorption and decent light scattering from Pt. This improved light-harvesting property of the structure is beneficial for solar water splitting devices. Therefore, a suitable Pt NPs layer on the FTO substrate leads to a significant improvement in PEC water oxidation of hematite not only due to electronic effects but also due to light trapping. Another crucial role in engineering optimized hematite based photoanodes is the presence of the $\mathrm{Fe}_{2} \mathrm{TiO}_{5}$ layer around the $\mathrm{Fe}_{2} \mathrm{O}_{3}$ particles. This is evident from the photocurrent data in Figure 3a; for those electrodes the photocurrent density reaches up to $1.0 \mathrm{~mA} \mathrm{~cm}^{-2}$ at $1.23 \mathrm{~V}_{\mathrm{RHE}}$, and a photocurrent density of $2.4 \mathrm{~mA} \mathrm{~cm}^{-2}$ at $1.6 \mathrm{~V}_{\mathrm{RHE}}$ is obtained. The photocurrent transient ratio values $\left(i_{\text {steady }} / i_{\text {initial }}\right)$ reach $0.84-0.95$ for the $\mathrm{Fe}_{2} \mathrm{O}_{3}$ on planar or Pt/FTO substrates, whereas for the Ti-modification, the $i_{\text {steady }} / i_{\text {initial }}$ value close to one is obtained (Figure 3c). From the comparison it is evident that the combination of the $\mathrm{Fe}_{2} \mathrm{TiO}_{5}$ shell and the Pt underlayer are particularly effective in reducing/eliminating the decay of the photocurrent, i.e. lead to rectangular phototransients which are indicative of a strong elimination of charge accumulation effects.

Figure $3 \mathrm{~d}$ shows the results of photocurrent spectra given as incident photon-to-current conversion efficiencies (IPCEs) versus incident light wavelength measured at $1.5 \mathrm{~V}_{\mathrm{RHE}}$ in $1 \mathrm{M}$ $\mathrm{KOH}$. The IPCE values are in line with the measurements using AM 1.5G sun light irradiation (Figure 3a). The introduction of both $\mathrm{Fe}_{2} \mathrm{TiO}_{5}$ surface layer and a $\mathrm{Pt}$ underlayer on the hematite photoanode leads to significantly enhanced IPCE values compared to pristine hematite on FTO or Pt/FTO substrates. More specifically, over the entire spectral range from $320 \mathrm{~nm}$ to $650 \mathrm{~nm}$, the $\mathrm{Fe}_{2} \mathrm{TiO}_{5} / \mathrm{Fe}_{2} \mathrm{O}_{3} / \mathrm{Pt}$ photoanodes show the highest IPCE value, and at 
the maximum IPCE value around $340 \mathrm{~nm}$ is $\sim 37 \%$. The IPCE data are plotted for the evaluation of an indirect band gap $\left(E_{\mathrm{g}}\right)$ as shown in Figure $3 \mathrm{e}$. The resulting $E_{\mathrm{g}}$ values are in the order of 2.1 2.2 eV for the hematite on FTO or Pt/FTO substrates, while for the $\mathrm{Fe}_{2} \mathrm{TiO}_{5} / \mathrm{Fe}_{2} \mathrm{O}_{3} / \mathrm{Pt}$ photoanode, it shows a shift to a lower value of which can be attributed to contributions from $\mathrm{Fe}_{2} \mathrm{TiO}_{5}$. In literature the energetic positions of $\mathrm{Fe}_{2} \mathrm{O}_{3}$ and $\mathrm{Fe}_{2} \mathrm{TiO}_{5}$ are generally as shown in Figure S11. ${ }^{[20,31]}$ Non vertical transitions in the junction may cause the apparent lowering of the bandgap.

To further explore charge transfer and recombination processes at the $\mathrm{Pt}$ and $\mathrm{Fe}_{2} \mathrm{TiO}_{5}-$ treated $\mathrm{Fe}_{2} \mathrm{O}_{3}$ photoanodes, electrochemical impedance spectroscopy (EIS) measurements were carried out as shown in Figure $3 f$. The semiconductor-electrolyte charge resistance $\left(R_{c t}\right)$ is a key parameter in characterizing the semiconductor-electrolyte charge-transfer process. In a Nyquist plot of the AC impedance data, the diameter of the skewed semicircle reflects $R_{c t}$. In our case, $R_{c t}$ was calculated by fitting an equivalent circuit as shown in the inset of Figure 3f and S12 to the impedance data. In Figure S12, the $\mathrm{R}_{\mathrm{ct}}$ for the $\mathrm{Fe}_{2} \mathrm{TiO}_{5}$ treated $\mathrm{Fe}_{2} \mathrm{O}_{3}$ on $\mathrm{Pt} / \mathrm{FTO}(1203 \Omega)$ is clearly smaller than those of the pristine sample $(2544 \Omega)$ and $\mathrm{Fe}_{2} \mathrm{O}_{3}$ on Pt/FTO $(1480 \Omega)$, and the charge transfer resistance value for the $\mathrm{Fe}_{2} \mathrm{O}_{3}$ on Pt/FTO $(1480 \Omega)$ is also smaller than that of the pristine one $(2544 \Omega)$. This confirms that the decoration with iron titanate catalysts significantly increases the interfacial charge-transfer rate across the semiconductor-electrolyte interface. This reduces the recombination of carriers at this interface, and thus enhances the resulting photocurrent. ${ }^{[21,32]}$ Moreover, the data also show that the Pt underlayer facilitates the electron transfer to and across the back contact. To additionally support these findings $\mathrm{H}_{2} \mathrm{O}_{2}$ was added into the electrolyte as a hole scavenger for the LSV measurements under AM 1.5G illumination. ${ }^{[33]}$ The photocurrents of $\mathrm{Fe}_{2} \mathrm{O}_{3} / \mathrm{Pt}$ and $\mathrm{Fe}_{2} \mathrm{TiO}_{5} / \mathrm{Fe}_{2} \mathrm{O}_{3} / \mathrm{Pt}$ photoanodes (Figure S13) are significantly higher than that of the pristine $\mathrm{Fe}_{2} \mathrm{O}_{3}$, suggesting that the improvement in photoresponse can be attributed to an 
overall better charge management between the hole transfer at the $\mathrm{Fe}_{2} \mathrm{TiO}_{5} /$ electrolyte interface and the decreased interfacial resistance provided by the Pt/FTO contact.

Figure 4a shows the efficiency of charge transport in the sample calculated as $J_{\mathrm{H}_{2} \mathrm{O}}=J_{\text {max }} \times \eta_{\text {abs }} \times \eta_{\text {sep }} \times \eta_{\text {int. }}{ }^{[22]} J_{\text {max }}$ is expressed as the incident spectral irradiance over wavelengths below $580 \mathrm{~nm}$, which is the absorption band edge of $\alpha-\mathrm{Fe}_{2} \mathrm{O}_{3}$, and $\eta_{\text {abs }}$ is defined as the product of the incident spectral irradiance and the light harvesting efficiency $\left(\eta_{\mathrm{LH}}\right)$ at each wavelength, dividing by $J_{\max }\left(11.4 \mathrm{~mA} \mathrm{~cm}{ }^{-2}\right) \cdot{ }^{[34]}$ The charge separation efficiency is relevant to the bulk electron-hole recombination, while the interfacial charge transfer efficiency $\left(\eta_{\text {int }}\right)$ is correlated to the surface electron-hole recombination. The hole scavenger experiment shows that if $\mathrm{H}_{2} \mathrm{O}_{2}$ is added to the electrolyte, the $\eta_{\text {int }}$ is close to $100 \%{ }^{[22,35,36]}$ The charge separation efficiency can be calculated as $\eta_{\text {abs }} \times \eta_{\text {sep }} \approx J_{\left(\mathrm{KOH}+\mathrm{H}_{2} \mathrm{O}_{2}\right.} / J_{\text {max }}$, where $J_{\left(\mathrm{KOH}+\mathrm{H}_{2} \mathrm{O}_{2}\right)}$ is the photocurrent density for $\mathrm{H}_{2} \mathrm{O}_{2}$ oxidation. The $\eta_{\text {abs }} \times \eta_{\text {sep }}$ value of $\mathrm{Fe}_{2} \mathrm{O}_{3}$ photoanode is $14 \%$ at $1.23 \mathrm{~V}_{\text {RHE }}$ (Figure $4 \mathrm{a}$ ). Upon the $\mathrm{Fe}_{2} \mathrm{TiO}_{5}$ and Pt NPs treatment, the $\eta_{\text {abs }} \times \eta_{\text {sep }}$ value reaches up to $21-24 \%$ at $1.23 \mathrm{~V}_{\mathrm{RHE}}$ (Figure $4 \mathrm{a}$ ). Furthermore, the surface charge transfer efficiency $\left(\eta_{\text {surf }}\right)$ can be obtained from the ratio of $J_{\mathrm{KOH}} / J_{\left(\mathrm{KOH}+\mathrm{H}_{2} \mathrm{O}_{2}\right)}$ as shown in Figure 4 b. The calculated efficiency shows that $\eta_{\text {surf }}$ for the $\mathrm{Fe}_{2} \mathrm{TiO}_{5} / \mathrm{Fe}_{2} \mathrm{O}_{3} / \mathrm{Pt}$ photoanode (43\% at 1.23 $\mathrm{V}_{\mathrm{RHE}}$ ) is higher than those of the pristine $\mathrm{Fe}_{2} \mathrm{O}_{3}\left(32 \%\right.$ at $\left.1.23 \mathrm{~V}_{\mathrm{RHE}}\right)$ and $\mathrm{Fe}_{2} \mathrm{O}_{3} / \mathrm{Pt}(27 \%$ at 1.23 $\mathrm{V}_{\mathrm{RHE}}$ ) photoanodes. Thus, in line with above results, it can be ascribed to the combined effect of $\mathrm{Fe}_{2} \mathrm{TiO}_{5}$ and $\mathrm{Pt}$ on the improved charge separation efficiency and the reduced surface and interface recombinations. The reduced surface recombination is attributed to the $\mathrm{Fe}_{2} \mathrm{TiO}_{5}$, while the reduced interface recombination is due to the presence of Pt NPs layer facilitating the electron transfer to the back contact.

In the light absorption data in Figure $3 \mathrm{~b}-$ it is clear that the effect of $\mathrm{Pt}$ is based on two effects. Pt not only provides a sink effect that aids electron transfer from the hematite to the back side, but also the structured electrode provides significantly enhanced light absorption properties. The light harvesting efficiency $\left(\eta_{\mathrm{LH}}\right)$ of $\mathrm{Fe}_{2} \mathrm{O}_{3}$ on Pt/FTO (Figure 4c) calculated 
from the UV-Vis absorbance (Figure 3b) is obviously strongly increased compared to the pristine one, which is an additional reason for the improved photoresponse of $\mathrm{Fe}_{2} \mathrm{O}_{3} / \mathrm{Pt}$ and $\mathrm{Fe}_{2} \mathrm{TiO}_{5} / \mathrm{Fe}_{2} \mathrm{O}_{3} / \mathrm{Pt}$ photoanodes.

\section{Conclusion}

In summary, we describe an optimized scheme to overcome charge accumulation and transport problems on hematite photoanodes which together with an enhanced light trapping lead to significantly enhanced photoelectrochemical water splitting efficiency. A facile method, combining metallic replacement with hydrolytic reactions, is used for the decoration of metal Pt nanoparticles and pillars on FTO substrates. The Pt structures can be optimized towards a light trapping structure. If decorated with hematite this leads to the increased light harvesting efficiency and PEC activity. Furthermore, the conversion of the outmost part of the hematite to $\mathrm{Fe}_{2} \mathrm{TiO}_{5}$ on the $\mathrm{Fe}_{2} \mathrm{O}_{3} / \mathrm{Pt}$ photoanode gives rise to an even more significant enhancement of the electrode for PEC water splitting. The final $\mathrm{Fe}_{2} \mathrm{TiO}_{5} / \mathrm{Fe}_{2} \mathrm{O}_{3} / \mathrm{Pt}$ photoanode exhibits photocurrent for water oxidation of $1.0 \mathrm{~mA} \mathrm{~cm}^{-2}$ and $2.4 \mathrm{~mA} \mathrm{~cm}^{-2}$ at $1.23 \mathrm{~V}_{\mathrm{RHE}}$ and at 1.6 $\mathrm{V}_{\text {RHE}}$. Underlying reasons are that the $\mathrm{Fe}_{2} \mathrm{TiO}_{5}$ shell drives holes to the surface for water oxidation, while the Pt nanoparticles underlayer facilitates the electrons to the opposite direction. These findings demonstrate the synergistic effect of $\mathrm{Fe}_{2} \mathrm{TiO}_{5}$ and $\mathrm{Pt}$ layers on hematite for the improvement of PEC water oxidation. 


\section{Experimental Section}

The hematite photoanodes were prepared by a simple solution-based method. The starting $\mathrm{FeOOH}$ was grown on fluorine doped tin oxide (FTO) in an aqueous solution containing $\mathrm{Fe}\left(\mathrm{NO}_{3}\right)_{3}(20 \mathrm{mM})($ Sigma-Aldrich, $99 \%)$ at $70{ }^{\circ} \mathrm{C}$ for $2 \mathrm{~h}$. After drying at room temperature, the thin films were annealed at $600{ }^{\circ} \mathrm{C}$ for $30 \mathrm{~min}$ and then $750{ }^{\circ} \mathrm{C}$ for $20 \mathrm{~min}$ in a furnace (HF-Kejing Furnace, KSL-1100X) to obtain $\mathrm{Fe}_{2} \mathrm{O}_{3}$ samples. For the $\mathrm{Fe}_{2} \mathrm{O}_{3} / \mathrm{Pt}$ sample, the $\mathrm{Pt}$ NPs were deposited on the FTO substrates initially. The FTO substrate was immersed in a $\mathrm{H}_{2} \mathrm{PtCl}_{6}$ (Sigma-Aldrich, 99.9\%) solution $(5-20 \mathrm{mM})$, and then a pure iron foil was put in the solution facing to the FTO substrate. The Pt NPs were reduced by the iron and then deposited on the FTO. Then the Pt/FTO was taken and washed with distilled water drying with air. The $\mathrm{Pt} / \mathrm{FTO}$ was immersed in $\mathrm{Fe}\left(\mathrm{NO}_{3}\right)_{3}$ solution $(20 \mathrm{mM})$ at $70{ }^{\circ} \mathrm{C}$ for various duration times. The $\mathrm{FeOOH} / \mathrm{Pt}$ thin film was washed with deionized water and then annealed at $600{ }^{\circ} \mathrm{C}$ for $30 \mathrm{~min}$ and then $750{ }^{\circ} \mathrm{C}$ for 20 min finally. For the formation of $\mathrm{Fe}_{2} \mathrm{TiO}_{5} / \mathrm{Fe}_{2} \mathrm{O}_{3} / \mathrm{Pt}$ sample, the $\mathrm{FeOOH} / \mathrm{Pt}$ sample was immersed in $\mathrm{TiCl}_{4}$ (Sigma-Aldrich, 99\%) aqueous solution, and then dried with air, following with thermal treatment at $600{ }^{\circ} \mathrm{C}$ and $750{ }^{\circ} \mathrm{C}$, respectively.

The photoelectrochemical water splitting was performed in a three-electrode cell with the photoanode as a working electrode, a platinum foil as a counter electrode, and $\mathrm{Ag} / \mathrm{Ag} / \mathrm{Cl}$ (3 M) as a reference electrode in $\mathrm{KOH}$ solution $(1 \mathrm{M})$. Photocurrent-potential curves were recorded under AM 1.5G sun illumination $\left(100 \mathrm{~mW} \mathrm{~cm} \mathrm{~cm}^{-2}\right)$. Photocurrent spectra were acquired at an applied potential of $0.5 \mathrm{~V}$ (vs. $\mathrm{Ag} / \mathrm{AgCl}(3 \mathrm{M} \mathrm{KCl}))$ in $\mathrm{KOH}(1 \mathrm{M})$ recorded with $20 \mathrm{~nm}$ steps in the range of 300-700 nm using an Oriel $6365150 \mathrm{~W}$ Xe-lamp equipped with an Oriel Cornerstone 7400 1/8 m monochromator. Electrochemical impedance spectra (EIS) were recorded at applied potential of $0.23 \mathrm{~V}$ ( $\mathrm{vs} \mathrm{Ag} / \mathrm{AgCl}$ ) and an $\mathrm{AC}$ potential 
frequency range of $10^{5}-0.01 \mathrm{~Hz}$ with an amplitude of $10 \mathrm{mV}$ under $\mathrm{AM} 1.5 \mathrm{G}$ sun illumination $\left(100 \mathrm{~mW} \mathrm{~cm}^{-2}\right)$.

X-ray diffraction (X'pert Philips PRO with a Panalytical X'celerator detector, Germany) was carried out using graphite monochromized $\mathrm{Cu} \mathrm{K}_{\alpha}$ radiation (Wavelength $1.54056 \AA$ ). Chemical characterization was carried out by a X-ray photoelectron spectraoscopy (ESCALAB 250Xi, ThermoFisher Scientific). A field-emission scanning electrode microscope (Hitachi SU8020, Japan) was used for the morphological characterization of the electrodes. TEM analysis was performed on a TECNAI G ${ }^{2}$ TF20 microscope operated at 200 $\mathrm{kV}$. UV-vis diffuse reflectance spectra were taken on an UV-2550 (Shimadzu) spectrometer by using $\mathrm{BaSO}_{4}$ as the reference.

\section{Acknowledgements}

The work was supported by the National Science Foundation of China (21622310, 21573264, 21633013). 
References

[1] K. Sivula, F. L. Formal, M. Grätzel, ChemSusChem 2011, 4, 432-449.

[2] S. H. Shen. S. A. Lindley, X. Y. Chen, J. Z. Zhang, Energy Environ. Sci. 2016, 9, 2744-2775.

[3] S. Kment, F. Riboni, S. Pausova, L. Wang, L. Y. Wang, H. Han, Z. Hubicka, J. Krysa, P. Schmuki, R. Zboril, Chem. Soc. Rev. 2017, DOI: 10.1039/C6CS00015K.

[4] C. Li, A. Li, Z. Luo, J. Zheng, X. Chang, Z. Huang, T. Wang, J. L. Gong, Angew. Chem. Int. Ed. 2017, 129, 4214-4219.

[5] P. S. Shinde, M. A. Mahadik, S. Y. Lee, J. Ryu, S. H. Choi, J. S. Jang, Chem. Engineering J. 2017, 320, 81-92.

[6] L. Wang, N. T. Nguyen, Y. Zhang, Y. P. Bi, P. Schmuki, ChemSusChem 2017, 10, $720-2727$.

[7] J. Li, S. K. Cushing, P. Zheng, F. Meng, D. Chu, N. Wu, Nature Commun. 2013, 4, 2651.

[8] H. Gao, C. Liu, H. E. Jeong, P. Yang, ACS Nano 2011, 6, 234-240.

[9] A. Müller, I. Kondofersky, A. Folger, D. Fattakhova-Rohlfing, T. Bein, C. Scheu, Mater. Res. Express 2017, 4, 016409.

[10] H. Dotan, O. Kfir, E. Sharlin, O. Blank, M. Gross, I. Dumchin, G. Ankonina, A. Rothschild, Nature Mater. 2013, 12, 158-164.

[11] Y. Qiu, S.-F. Leung, Q. Zhang, B. Hua, Q. Lin, Z. Wei, K.-H. Tusi, Y. Zhang, S. Yang, Z. Fan, Nano Lett. 2014, 14, 2123-2129.

[12] X. Wang, K. Peng, Y. Hu, F. Zhang, B. Hu, L. Li, M. Wang, X.-M. Meng, S.-T. Lee, Nano Lett. 2014, 14, 18-23.

[13] H. Kim, C. M. Gilmore, A. Piqué, J. S. Horwitz, H. Mattoussi, H. Murata, Z. H. Kafafi, D. B. Chrisey, J. Appl. Phys. 1999, 86, 6451. 
[14] S. R. Pendlebury, A. J. Cowan, M. Barroso, K. Sivula, J. Ye, M. Grätzel, D. R. Klug, J. Tang, J. R. Durrant, Energy Environ. Sci. 2012, 5, 6304.

[15] L. Steier, I. Herraiz-Cardona, S. Gimenez, F. Fabregat-Santiago, J. Bisquert, S. D. Tilley, M. Grätzel, Adv. Func. Mater. 2014, 23, 7681.

[16] T. Hisatomi, H. Dotan, M. Stefik, K. Sivula, A. Rothschild, M. Grätzel, N. Mathews, Adv. Mater. 2012, 24, 2699.

[17] R. Gutkowski, W. Schuhmann, Phys. Chem. Chem. Phys. 2016, 18, 10758-10763..

[18] R. Gutkowski, D. Peeters. W. Schuhmann, J. Mater. Chem. A 2016, 4, 7875-7882.

[19] J. J. Deng, X. X. Lv, J. Y. Liu, H. Zhang, C. H. Hong, J. O. Wang, X. H. Sun, J. Zhong, S. T. Lee, ACS Nano 2015, 9, 5348-5356.

[20] P. S. Bassi, R. P. Antony, P. P. Boix, Y. Fang, J. Barber, L. H. Wong, Nano Energy 2016, 22, 310-318.

[21] C. Li, T. Wang, Z. Luo, S. Liu, J. L. Gong, Small 2016, 12, 3415-3422.

[22] J. Y. Kim, D. H. Youn, K. Kang, J. S. Lee, Angew. Chem. Int. Ed. 2016, 26, 1985410858 .

[23] S. Mukerjee, S. Srinivasan, M. P. Soriaga, J. Phys. Chem. 1995, 99, 4577-4589.

[24] Z. R. Dai, S. Sun, Z. L. Wang, Nano Lett. 2001, 1, 443-447.

[25] D. L. A. de Faria, S. Venâncio Silva, M. T. de Oliveira, J. Raman Spectrosc. 1997, 28, 873-878.

[26] Q. Liu, J. He, T. Yao, Z. Sun, W. Cheng, S. He, Y. Xie, Y. Peng, H. Cheng, Y. Sun, Y. Jiang, F. Hu, Z. Xie, W. Yan, Z. Pan, Z. Wu, S. Wei, Nature Commun. 2014, 5, 5122.

[27] J. C. Vedrine, M. Dufaux, C. Naccache, B. Imelik, J. Chem. Soc. Faraday Trans 1978, $74,440-449$.

[28] Y.-S. Hu, A. Kleinman-Shwarsctein, A. J. Forman, D. Hazen, J.-N. Park, E. W. McFarland, Chem. Mater. 2008, 20, 3803-3805.

[29] M. E. A. Warwick, D. Barreca, E. Bontempi, G. Carraro, A. Gasparotto, C. Maccato, 
K. Kaunisto, T.-P. Ruoko, H. Lemmetyinen, C. Sada, Y. Gönüllü, S. Mathur, Phys. Chem. Chem. Phys. 2015, 17, 12899-12907.

[30] L. Wang, C.-Y. Lee, P. Schmuki, J. Mater. Chem. A 2013, 1, 212-215.

[31] P. S. Bassi, S. Y. Chiam, Gurudayal, J. Barber, L. H. Wong, ACS Appl. Mater. Interfaces 2014, 6, 22490-22495.

[32] L. Wang, N. T. Nguyen, P. Schmuki, ChemSusChem 2016, 9, 2048-2053.

[33] O. Zandi, T. W. Hamann, J. Phys. Chem. Letts. 2014, 5, 1522-1526.

[34] Z. Luo, C. Li, S. Liu, T. Wang, J. L. Gong, Chem. Sci. 2017, 8, 91-100.

[35] H. Dotan, K. Sivula, M. Grätzel, A. Rothschild, S. C. Warren, Energy Environ. Sci. 2011, 4, 958-964.

[36] Z. Luo, C. Li, S. Liu, T. Wang, J. L. Gong, Chem. Sci. 2017, 8, 91-100. 

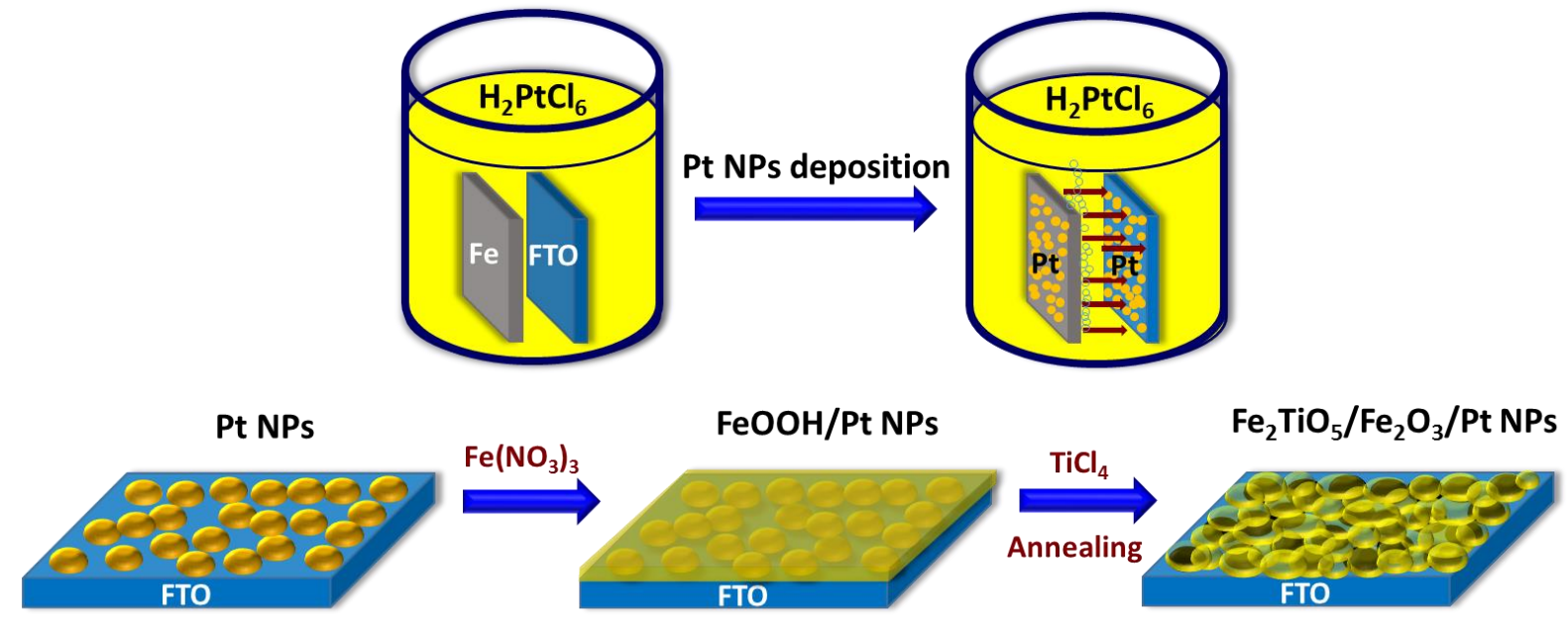

Scheme 1 Schematic diagram for the formation of $\mathrm{Fe}_{2} \mathrm{TiO}_{5} / \mathrm{Fe}_{2} \mathrm{O}_{3} / \mathrm{Pt}$. 

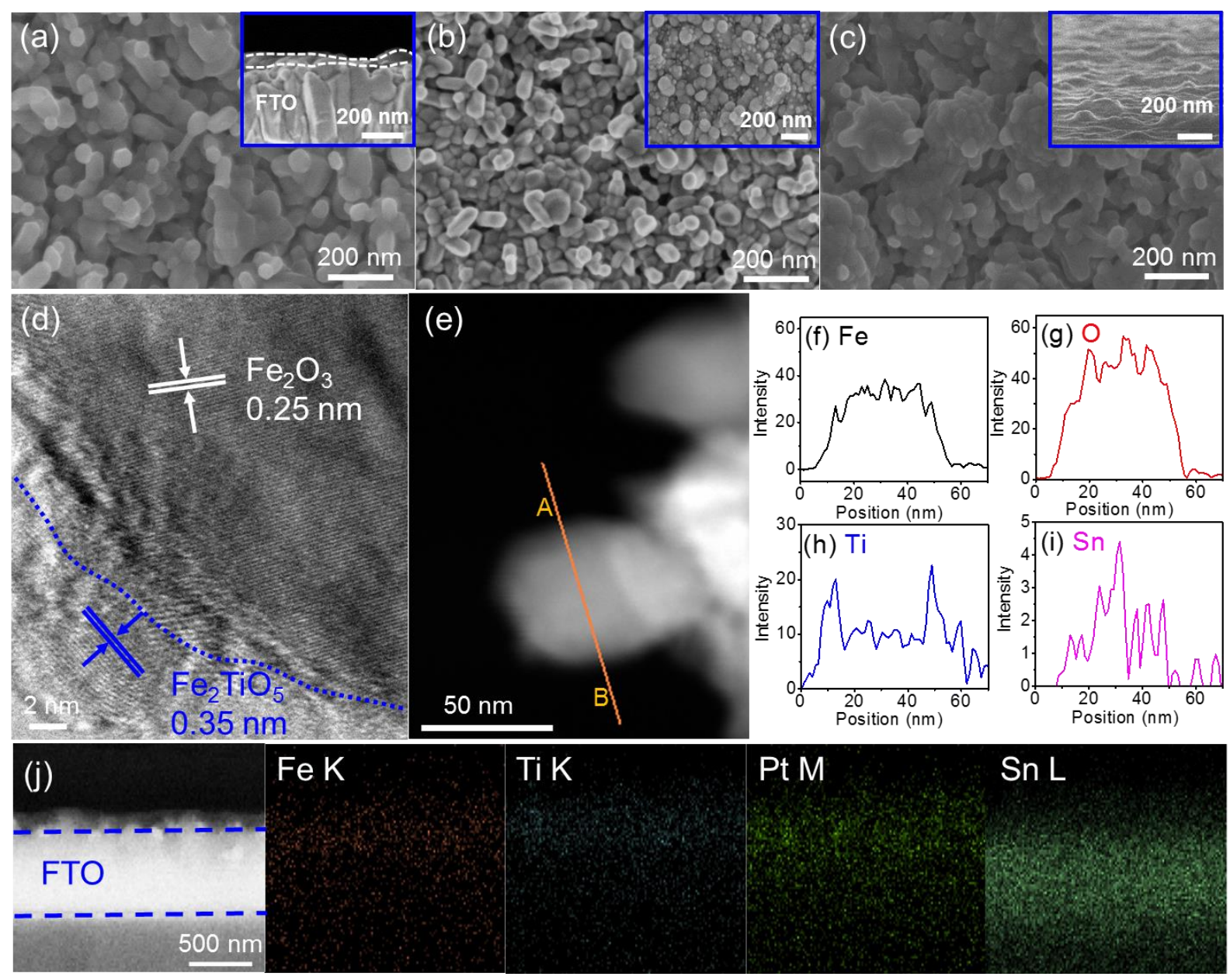

Figure 1 (a-c) SEM images of (a) $\mathrm{Fe}_{2} \mathrm{O}_{3}$, (b) $\mathrm{Fe}_{2} \mathrm{O}_{3} / \mathrm{Pt}$, and (c) $\mathrm{Fe}_{2} \mathrm{TiO}_{5} / \mathrm{Fe}_{2} \mathrm{O}_{3} / \mathrm{Pt}$. Inset of (a) and (c) show the cross sectional SEM images of $\mathrm{Fe}_{2} \mathrm{O}_{3}$ and $\mathrm{Fe}_{2} \mathrm{TiO}_{5} / \mathrm{Fe}_{2} \mathrm{O}_{3} / \mathrm{Pt}$. Inset of (b) shows the SEM image of Pt/FTO substrate; (d) HRTEM image of selected area of $\mathrm{Fe}_{2} \mathrm{TiO}_{5} / \mathrm{Fe}_{2} \mathrm{O}_{3} / \mathrm{Pt}$; (e) TEM image of a single particle; (f-i) $\mathrm{Fe}, \mathrm{O}$, Ti, and $\mathrm{Sn}$ element linedistribution in $\mathrm{Fe}_{2} \mathrm{TiO}_{5} / \mathrm{Fe}_{2} \mathrm{O}_{3} / \mathrm{Pt}$; (j) SEM mapping of $\mathrm{Fe}_{2} \mathrm{TiO}_{5} / \mathrm{Fe}_{2} \mathrm{O}_{3} / \mathrm{Pt}$. 

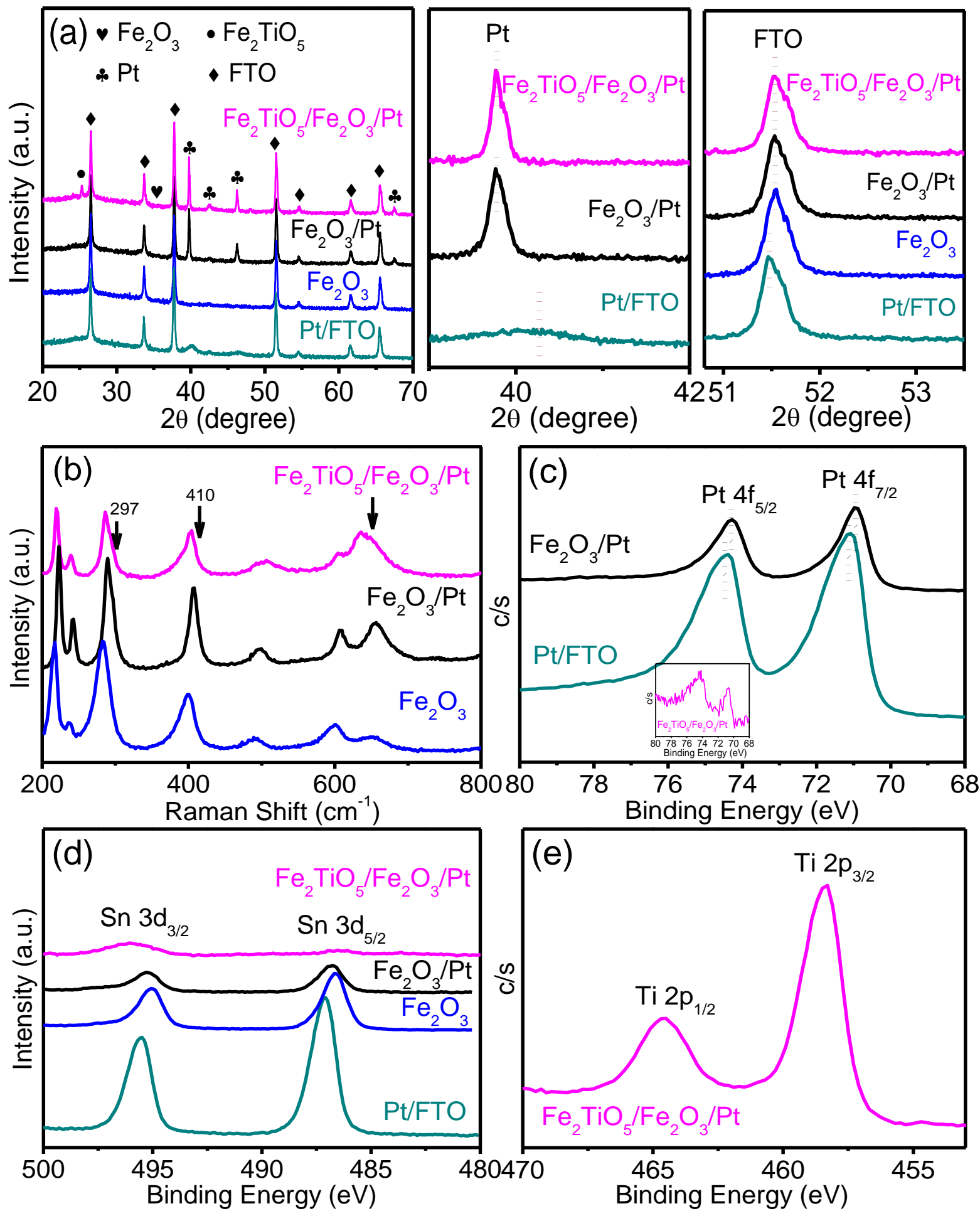

Figure 2 (a) XRD patterns, (b) Raman spectra, (c-e) XPS high resolution (c) Pt 4f, (d) Sn 3d, and (e) Ti 2p spectra of Pt/FTO, $\mathrm{Fe}_{2} \mathrm{O}_{3}, \mathrm{Fe}_{2} \mathrm{O}_{3} / \mathrm{Pt}$, and $\mathrm{Fe}_{2} \mathrm{TiO}_{5} / \mathrm{Fe}_{2} \mathrm{O}_{3} / \mathrm{Pt}$. 

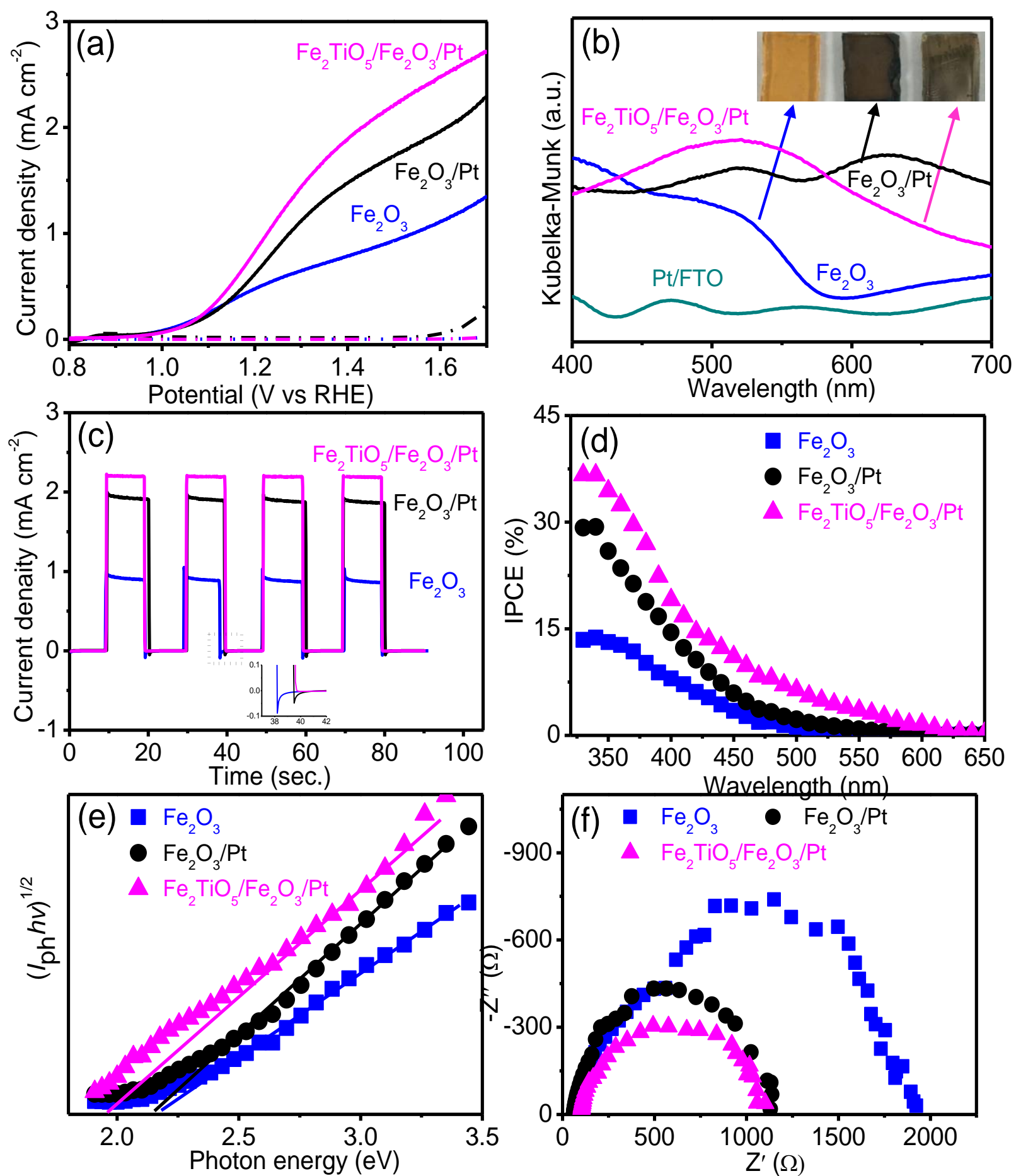

Figure 3 (a) Linear-sweep voltammogram (LSV) curves (line - in light; dash dot - in dark), (b) UV-Vis diffuse reflectance spectra, (c) $i$ - $t$ curves, (d) incident photon conversion efficiencies (IPCEs), (e) band gap determination from a ( $\left.i_{p h} h v\right)^{1 / 2}$ vs. photon energy (hv), (f) electrochemical impedance spectroscopy (EIS) of $\mathrm{Fe}_{2} \mathrm{O}_{3}, \mathrm{Fe}_{2} \mathrm{O}_{3} / \mathrm{Pt}$, and $\mathrm{Fe}_{2} \mathrm{TiO}_{5} / \mathrm{Fe}_{2} \mathrm{O}_{3} / \mathrm{Pt}$ photoanodes. The photoanodes were annealed at $600{ }^{\circ} \mathrm{C}$ for $30 \mathrm{~min}$ and then $750{ }^{\circ} \mathrm{C}$ for 20 min. The solar water splitting experiments were carried out in $1 \mathrm{M} \mathrm{KOH}$ electrolyte under AM $1.5 \mathrm{G}\left(100 \mathrm{~mW} \mathrm{~cm}^{-2}\right)$ illumination. The EIS measurement was carried out in $1 \mathrm{M} \mathrm{KOH}$ at $1.23 \mathrm{~V}_{\text {RHE}}$. Inset of (b) shows the optical images of samples. From left to right: $\mathrm{Fe}_{2} \mathrm{O}_{3}$, $\mathrm{Fe}_{2} \mathrm{O}_{3} / \mathrm{Pt}$, and $\mathrm{Fe}_{2} \mathrm{TiO}_{5} / \mathrm{Fe}_{2} \mathrm{O}_{3} / \mathrm{Pt}$. 

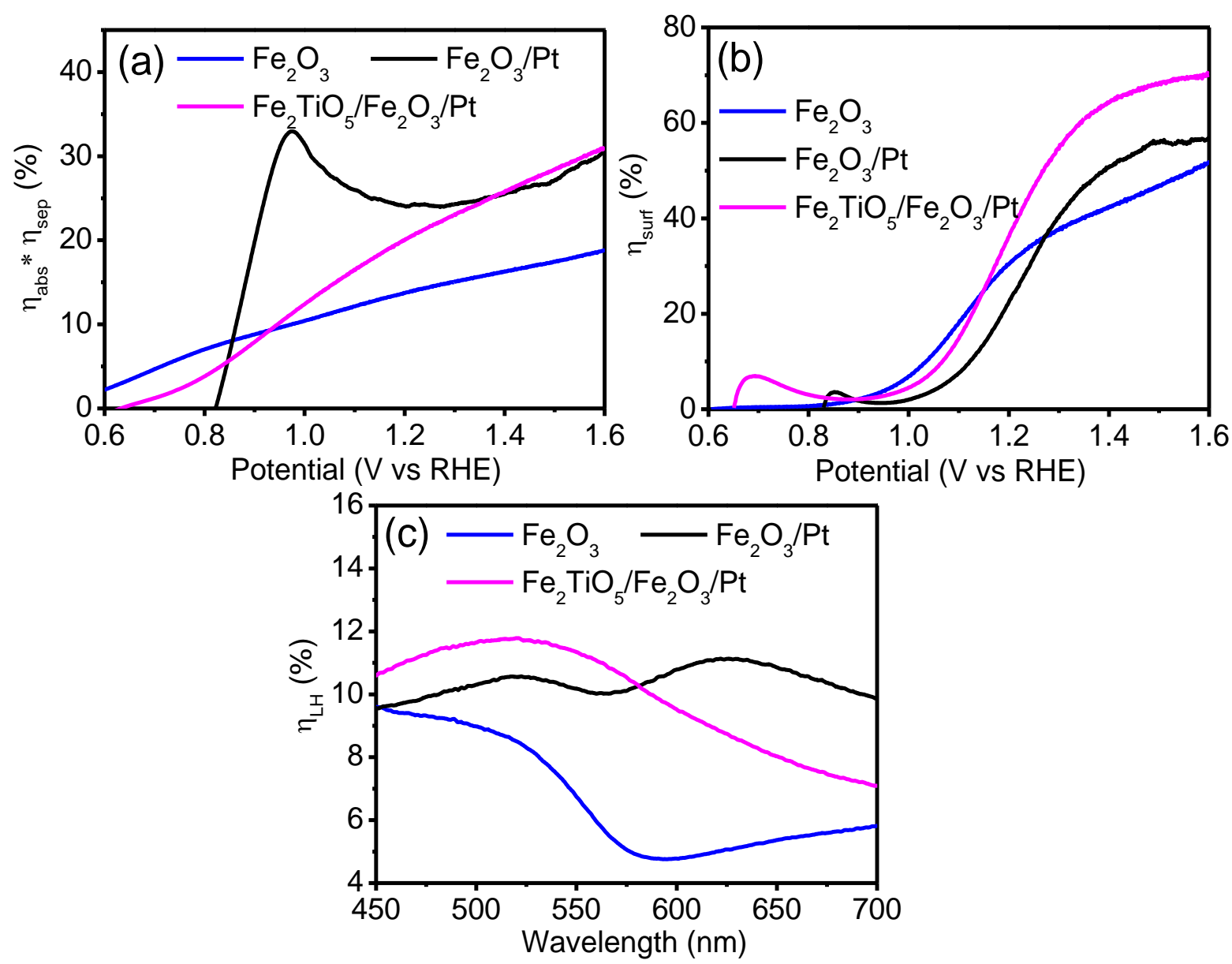

Figure 4 (a) Production of light absorption and charge separation efficiency $\left(\eta_{\text {abs }} \times \eta_{\text {sep }}\right)$, (b) surface charge separation efficiency $\left(\eta_{\text {surf }}\right)$, and (c) light harvesting efficiency $\left(\eta_{L H}\right)$ for $\mathrm{Fe}_{2} \mathrm{O}_{3}$, $\mathrm{Fe}_{2} \mathrm{O}_{3} / \mathrm{Pt}$, and $\mathrm{Fe}_{2} \mathrm{TiO}_{5} / \mathrm{Fe}_{2} \mathrm{O}_{3} / \mathrm{Pt}$ photoanodes. 